\title{
Glibenclamide (glyburide) delay electrocardiographic ST-segment elevation in a diabetic patient with acute myocardial infarction
}

\author{
Ying-Chih Chen ${ }^{1}$, Po-Chao Hsu ${ }^{1,3}$, Chun-Yuan Chu ${ }^{1}$, Wen-Hsien Lee ${ }^{1,2,3}$, Ho-Ming Su ${ }^{1,2,3}$, \\ Tsung-Hsien Lin ${ }^{1,3}$, Wen-Chol Voon ${ }^{1,3}$, Wen-Ter Lai ${ }^{1,3}$, Sheng-Hsiung Sheu ${ }^{1,3}$ \\ 1. Division of Cardiology, Department of Internal Medicine, Kaohsiung Medical University Hospital, Kaohsiung Medical \\ University, Kaohsiung, Taiwan. 2. Department of Internal Medicine, Kaohsiung Municipal Hsiao-Kang Hospital, Kaohsiung \\ Medical University, Kaohsiung, Taiwan. 3. Faculty of Medicine, College of Medicine, Kaohsiung Medical University, \\ Kaohsiung, Taiwan.
}

Correspondence: Wen-Hsien Lee. Address: Division of Cardiology, Department of Internal Medicine, Kaohsiung Medical University Hospital, 100 Tzyou 1st Road, Kaohsiung, Taiwan, ROC. Email: cooky-kmu@yahoo.com.tw

Received: January 5, 2015

Accepted: February 2, $2015 \quad$ Online Published: March 11, 2015

DOI : $10.5430 /$ crim.v2n2p31

URL: http://dx.doi.org/10.5430/crim.v2n2p31

\section{Abstract}

Acute myocardial infarction (AMI) is the most frequent cause of death worldwide. The timely diagnosis of AMI, especially ST-segment elevation myocardial infarction, is a key to successful management. A 12-lead electrocardiography (ECG) should be obtained and interpreted as soon as possible. The 12 lead ECG diagnosis may be more difficult in patients without diagnostic ST-segment elevation but with persistent typical ischemic symptoms. Here, we present a diabetic patient with AMI where the ST-segment elevation was masked by glibenclamide (glyburide) initially and delayed ECG change was revealed after glibenclamide was eliminated.

\section{Keywords}

Sulfonylurea, Glibenclamide, Glyburide, Acute coronary syndrome, Acute myocardial infarction

\section{I ntroduction}

Acute myocardial infarction (AMI) is the most frequent cause of death worldwide. The timely diagnosis of AMI, especially ST-segment elevation myocardial infarction, is a key to successful management. A 12-lead electrocardiography (ECG) should be obtained and interpreted as soon as possible ${ }^{[1]}$. We present a diabetic patient revealed delay electrocardiographic ST-segment elevation.

\section{Case report}

A 50-year-old male presented with persistent typical chest pain with radiation to the back for two hours and came to our emergency department for first aid. He had a past medical history of hypertension and diabetes mellitus for years. His oral antidiabetic agents were metformin $1000 \mathrm{mg}$ and glibenclamide (glyburide) $10 \mathrm{mg}$ twice daily. About eight hours before his chest pain, he took the last dose of metformin and glibenclamide. On arrival, his blood pressure was 134/86 mmHg and 
heart rate was 60 beats per minute. The 12 lead electrocardiography (ECG) showed no diagnostic ST-segment elevation (see Figure 1). The laboratory studies revealed white cell count: 9430/uL, hemoglobin: $12.9 \mathrm{~g} / \mathrm{dL}$, platelet count: 201000/uL, creatinine: $1.36 \mathrm{mg} / \mathrm{dL}$, creatine kinase: $380 \mathrm{IU} / \mathrm{L}$, creatine kinase MB: $6.4 \mathrm{IU} / \mathrm{L}$, troponin-I: $0.75 \mathrm{ng} / \mathrm{mL}$, total cholesterol: $233 \mathrm{mg} / \mathrm{dL}$ and LDL: $122 \mathrm{mg} / \mathrm{dL}$ (our lab data normal range listed in Table 1). The chest computed tomography revealed no aortic dissection. The acute myocardial infarction (AMI) was impressed by clinical presentation. Aspirin and clopidogrel were loaded and enoxaparin was given for anticoagulation. Four hours after his chest pain presentation, 12 lead ECG showed the same ST-segment shape, but emergency coronary angiogram revealed total occlusion in the proximal left anterior descending artery (LAD) (see Figure 2). The culprit lesion of LAD was successfully ballooned and stented. Thrombolysis in Myocardial Infarction III flow of the LAD was observed after percutaneous coronary intervention (see Figure 3). The patient's chest pain became relieved after coronary intervention. Six hours after his chest pain presentation, his ECG showed delayed ST-segment elevation over lead V2 to V5 (see Figure 4). The peak of cardiac enzyme revealed creatine kinase MB: $43.4 \mathrm{IU} / \mathrm{L}$ and troponin-I: $60.57 \mathrm{ng} / \mathrm{mL}$ at eight hours after his chest pain presentation. The medication was dual anti-platelet agents initially and then we added angiotensin-converting enzyme inhibitor, beta blocker and statin during the hospitalization period. Four days later, he was discharged without any morbidity.

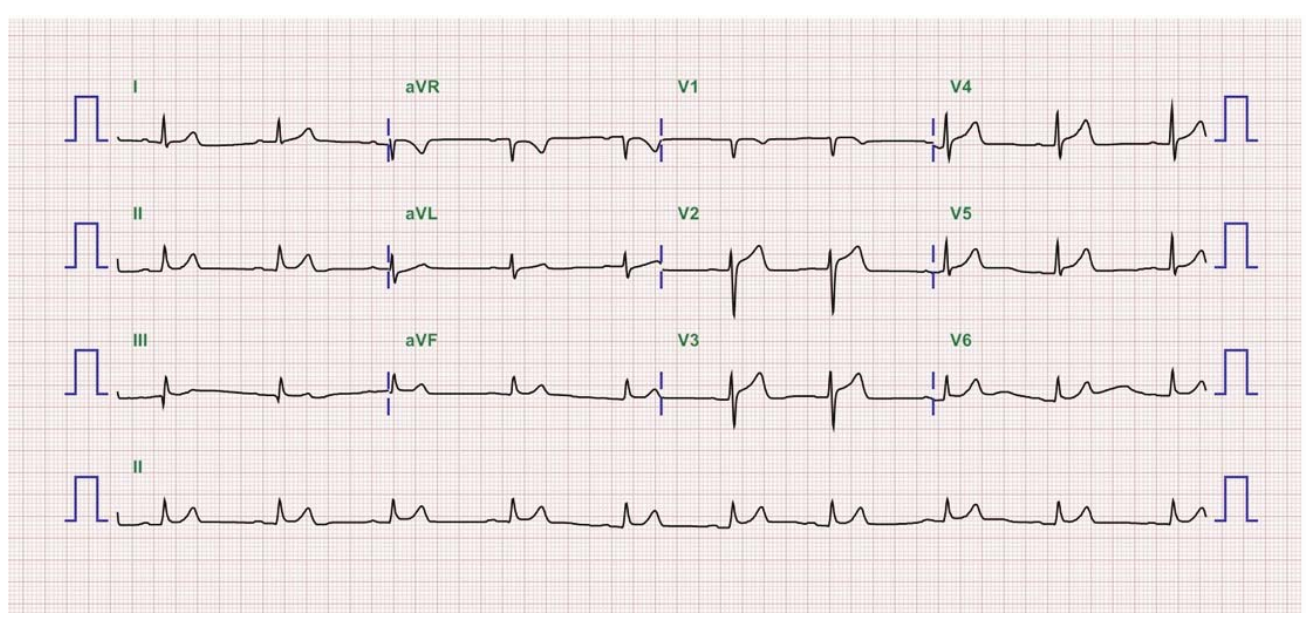

Figure 1. Initially, 12 lead electrocardiography revealed no diagnostic ST-segment elevation in the diabetic patient with ischemic chest pain.

Table 1. Our lab data normal range

\begin{tabular}{ll}
\hline White cell count & $4400 \sim 11300 / \mathrm{uL}$ \\
Hemoglobin & men: $14 \sim 17.5 \mathrm{~g} / \mathrm{dL}$ women: $12.3 \sim 15 \mathrm{~g} / \mathrm{dL}$ \\
Platelet & $172000 \sim 450000 / \mathrm{uL}$ \\
Creatinine & $0.6 \sim 1.3 \mathrm{mg} / \mathrm{dL}$ \\
Creatine kinase & $26 \sim 174 \mathrm{IU} / \mathrm{L}$ \\
Creatine kinase MB & $0.4 \sim 6.3 \mathrm{IU} / \mathrm{L}$ \\
Troponin-I & $<0.04 \mathrm{ng} / \mathrm{mL}$ \\
Total cholesterol & $140 \sim 200 \mathrm{mg} / \mathrm{dL}$ \\
LDL cholesterol & $<130 \mathrm{mg} / \mathrm{dL}$ \\
\hline
\end{tabular}




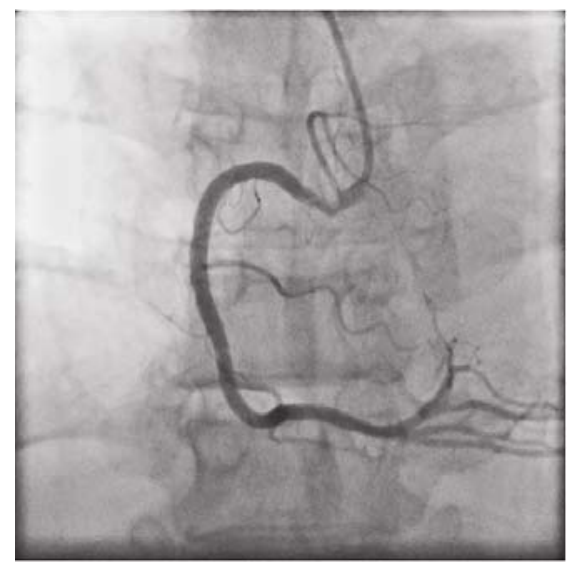

Figure 2a. Emergency coronary angiogram. Right coronary artery was patent

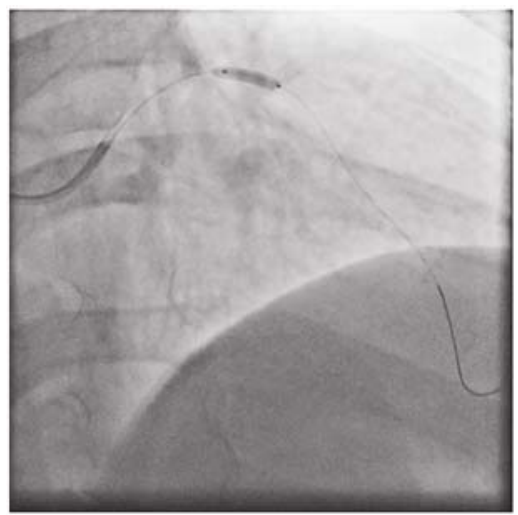

Figure 3a. After the culprit lesion of LAD was successfully ballooned and stented, Thrombolysis in Myocardial Infarction III flow of the LAD was observed. Balloon angioplasty

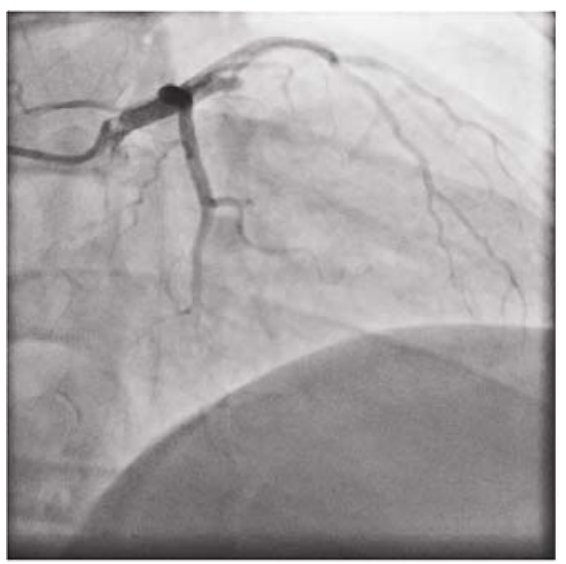

Figure $2 \mathbf{b}$. Total occlusion in the proximal left anterior descending artery (LAD)

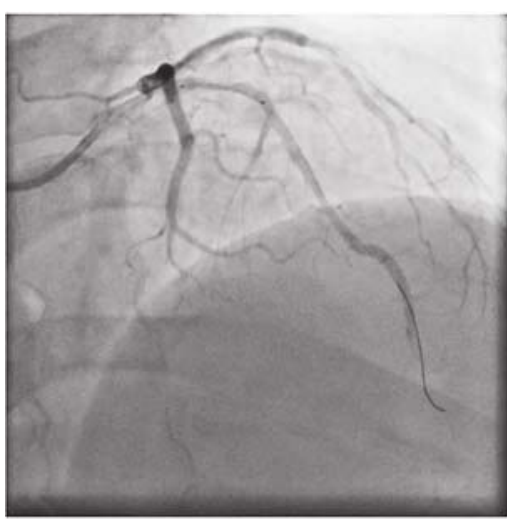

Figure 3b. Before stent deployment

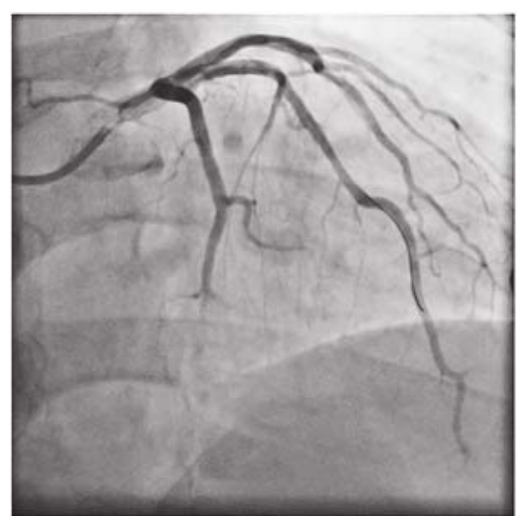

Figure 3c. Final coronary angiogram

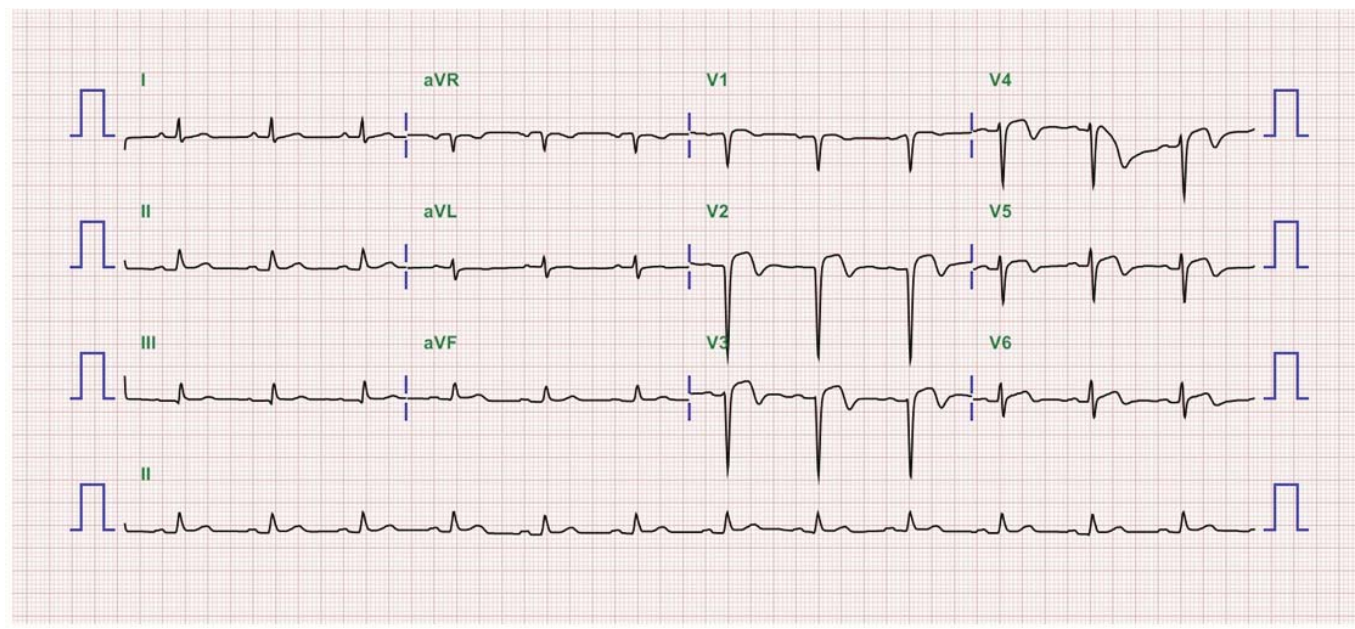

Figure 4. Twelve lead electrocardiography revealed delayed ST-segment elevation over lead V2 to V5 after glibenclamide was pharmacodynamically eliminated. 


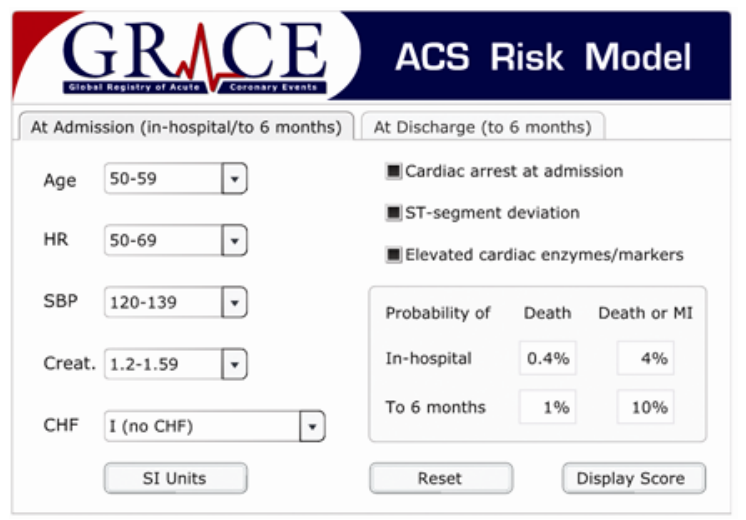

Figure 5a. Our patient's GRACE ACS risk score originally

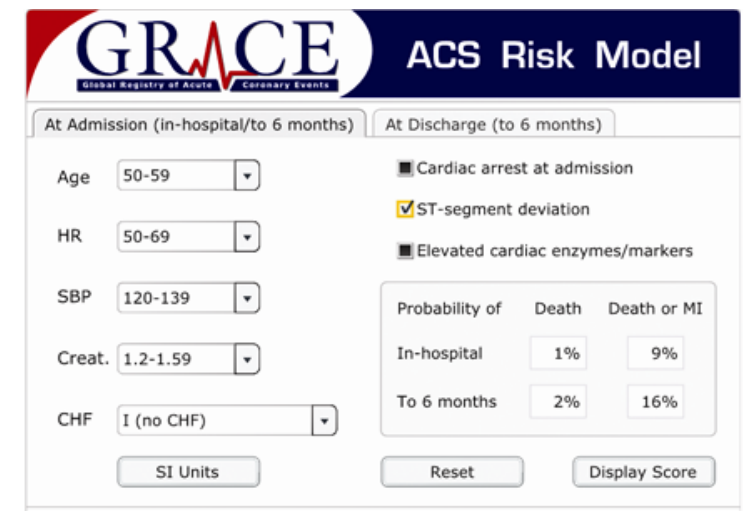

Figure 5b. Our patient's GRACE ACS risk score if exhibiting ECG ST-segment deviation

\section{Discussion}

AMI is the most frequent cause of death worldwide. The timely diagnosis of AMI, especially ST-segment elevation myocardial infarction (STEMI), is the key to successful management. A 12-lead ECG should be obtained and interpreted as soon as possible ${ }^{[1]}$. The ECG diagnosis may be more difficult in some cases with STEMI, included in the presence of bundle branch block, ventricular pacing or in a patient with persistent angina but without diagnostic ECG ${ }^{[1]}$. In the presented case, his ECG did not show ST-segment elevation initially but he exhibited persistent typical ischemic symptoms. Some iron channels were involved in the genesis of ECG ST-segment elevation. Previous studies have suggested that activation of sarcolemmal ATP-sensitive potassium (KATP) channels by ischemic ATP depletion may play a role ${ }^{[2]}$. One of this presented case's oral antidiabetic agents was glibenclamide, which may mask ECG ST-segment elevation. Sulfonylureas stimulate insulin secretion from pancreatic $\beta$-cells and are widely used to treat type 2 diabetes mellitus. Their major target is the KATP channel, which plays a significant role in influencing the $\beta$-cell membrane potential ${ }^{[3]}$. Glibenclamide, also known as glyburide, is a prototypical sulfonylurea that acts on KATP channels and blocks the protective effects of potassium channel openers ${ }^{[4]}$. Octameric KATP channels are composed of sulfonylurea receptors and potassium inward rectifier subunits ${ }^{[5]}$. Glibenclamide blocks KATP channels containing sulfonylurea receptor 1 ( $\beta$-cell type) and sulfonylurea receptor 2 (cardiac, smooth muscle types) subunits ${ }^{[3]}$.

In a cell model, Koster et al and Porks et al proposed the kinetic mechanism that demonstrated the relationship between sulfonylurea and potassium channel opener sensitivity of KATP subunits ${ }^{[3,5]}$. In an animal model, Kubota et al showed that ST-segment elevation during acute myocardial injury could be blunted by glibenclamide ${ }^{[6]}$. In a retrospective clinical study, Huizar et al showed that sulfonylureas may attenuate ST-segment elevation in diabetic patients with AMI ${ }^{[7]}$. The interaction between sulfonylurea and KATP channels is bidirectional control. In vivo, glibenclamide block of KATP channels is reversible ${ }^{[8]}$. Furthermore, the pharmacodynamical properties of glibenclamide after $20 \mathrm{mg}$ dosing exhibit a mean half-life of $3.3 \pm 1.5$ hours for the initial elimination phases ${ }^{[9]}$. In the presented case, we thought that glibenclamide initially blocked KATP channels and masked ECG change. After glibenclamide was pharmacodynamically eliminated, the delayed ST-segment elevation emerged.

\section{Conclusion}

Sulfonylureas may attenuate ST-segment elevation in diabetic patients with AMI and delayed ECG change may appear after sulfonylureas are pharmacodynamically eliminated. This condition really masked the mortality rate and might well have influenced our evaluation and management. Our patient's GRACE ACS risk score had been measured and revealed the probability of death in-hospital was $0.4 \%$; death or MI was $4 \%$ (see Figure 5). However, the probability of death 
in-hospital will elevate to $1 \%$ and death or MI to $9 \%$ if ECG shows ST-segment deviation initially (see Figure 6). Therefore, complete history taking and review of personal medication are very important clues for a diabetic patient in deciding on clinical management.

\section{Reference}

[1] Steg PG, James SK, Atar D, et al. Esc guidelines for the management of acute myocardial infarction in patients presenting with st-segment elevation. Eur Heart J. 2012; 33: 2569-2619. PMid:22922416 http://dx.doi.org/10.1093/eurheartj/ehs215

[2] Li RA, Leppo M, Miki T, et al. Molecular basis of electrocardiographic st-segment elevation. Circ Res. 2000; 87: 837-839. http://dx.doi.org/10.1161/01.RES.87.10.837

[3] Proks P, Reimann F, Green N, et al. Sulfonylurea stimulation of insulin secretion. Diabetes. 2002; 51 Suppl 3: S368-376. PMid:12475777 http://dx.doi.org/10.2337/diabetes.51.2007.S368.

[4] Jaburek M, Yarov-Yarovoy V, Paucek P, et al. State-dependent inhibition of the mitochondrial katp channel by glyburide and 5-hydroxydecanoate. J Biol Chem. 1998; 273: 13578-13582. PMid:9593694

[5] Koster JC, Sha Q, Nichols CG. Sulfonylurea and k(+)-channel opener sensitivity of k(atp) channels. Functional coupling of kir6.2 and sur1 subunits. J Gen Physiol. 1999; 114: 203-213. PMid:10435998 http://dx.doi.org/10.1085/jgp.114.2.203

[6] Kubota I, Yamaki M, Shibata T, et al. Role of atp-sensitive k+ channel on ecg st segment elevation during a bout of myocardial ischemia. A study on epicardial mapping in dogs. Circulation. 1993; 88: 1845-1851. PMid:8403330 http://dx.doi.org/10.1161/01.CIR.88.4.1845

[7] Huizar JF, Gonzalez LA, Alderman J, et al. Sulfonylureas attenuate electrocardiographic st-segment elevation during an acute myocardial infarction in diabetics. J Am Coll Cardiol. 2003; 42: 1017-1021. http://dx.doi.org/10.1016/S0735-1097(03)00916-1

[8] Ashcroft FM, Gribble FM. Tissue-specific effects of sulfonylureas: Lessons from studies of cloned k(atp) channels. J Diabetes Complications. 2000; 14: 192-196. http://dx.doi.org/10.1016/S1056-8727(00)00081-7

[9] Coppack SW, Lant AF, McIntosh CS, et al. Pharmacokinetic and pharmacodynamic studies of glibenclamide in non-insulin dependent diabetes mellitus. Br J Clin Pharmacol. 1990; 29: 673-684. PMid:2116159

http://dx.doi.org/10.1111/j.1365-2125.1990.tb03688.x 